\title{
A Targeting Strategy
}

ROSA26 genomic locus

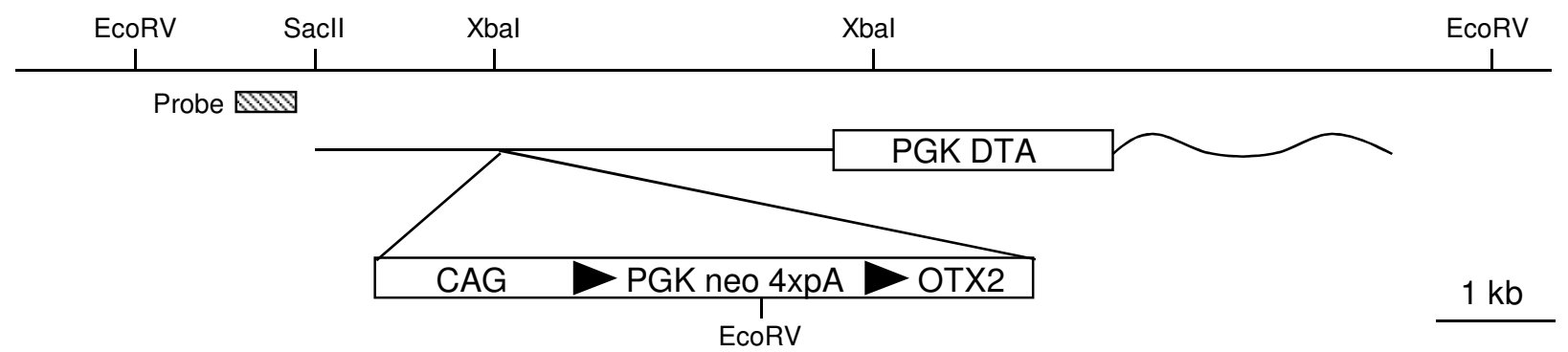

pROSA26-CAG-lox-stop-lox-OTX2

B

Southern Blot of ES Cell Clones

C OTX2 induction in ES Cells

$11 \mathrm{~kb}$

WT

3АЗ 3 А7 $3 B 9$

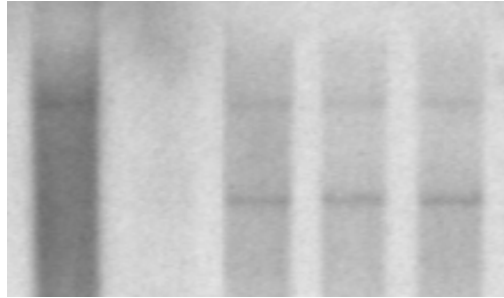

D

OTX2 induction in

whole cerebellum

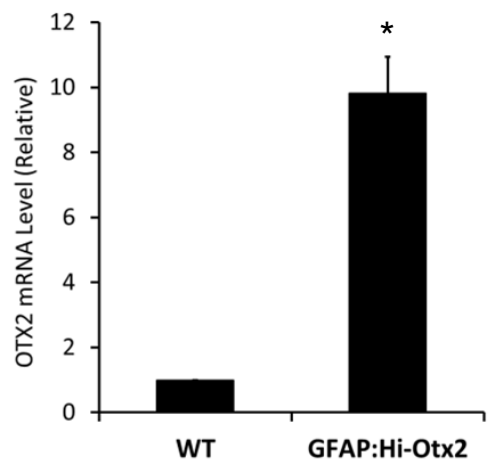

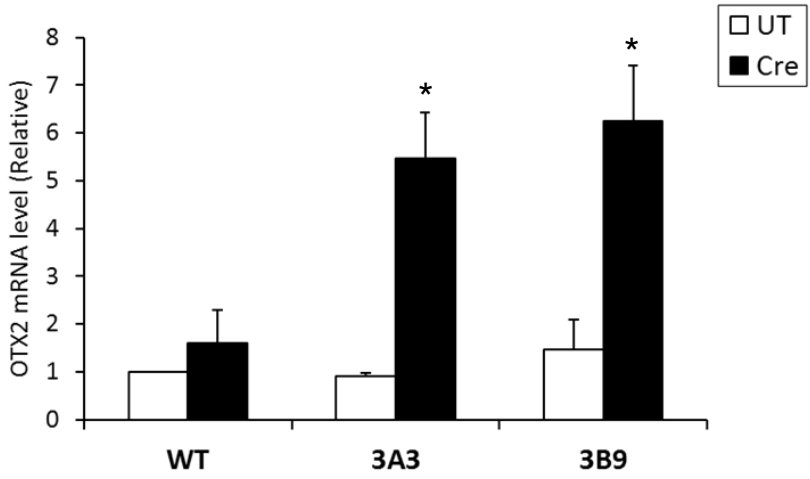

